\title{
Application of Remote Sensing Technology for Calibration of Bay of Bengal Morphology Model
}

\author{
Md. Misbah Uddin ${ }^{1}$, Dr. Md. Jahir Bin Alam ${ }^{1}$, Zahirul Haque Khan ${ }^{2}$, Md. \\ Mostafizur Rahman ${ }^{3}$, Md. Jaynal Islam Chowdhury ${ }^{4}$ \\ ${ }^{I}$ Department of Civil and Environmental Engineering, Shahjalal University of Science and Technology, Sylhet, \\ Bangladesh \\ ${ }^{2}$ Coast, Port and Estuary Division, Institute of Water Modelling, Dhaka, Bangladesh \\ ${ }^{3}$ Department of Urban and Regional Planning, RUET, Bangladesh \\ ${ }^{4}$ Engineers Office, Shahjalal University of Science and Technology, Sylhet, Bangladesh
}

\begin{abstract}
Prior to implication of mathematical model as a tool for any kind of policy making or decision making, the model must be calibrated against appropriate observed data. The two-dimensional sediment transport model of the Bay of Bengal usually being calibrated against suspended sediment concentration at different locations comparing the model results with field measurements to make the model performance to a satisfactory level. Since field data of sediment concentration is rarely available for model calibration, an attempt has been made in the present study, to generate sediment concentration data by using satellite images to calibrate the sediment transport model in a better way. Calibration of sediment transport model result against image generated sediment concentration at different locations of Bay of Bengal show acceptable agreement.
\end{abstract}

\section{Introduction}

The coast of Bay of Bengal is characteristically different from the other tropical coasts of the world primarily due to the huge amount of fresh water runoff $\left(1.5 \times 10^{12} \mathrm{~m}^{3}\right.$ per year $)$ and the associated sediment load (two billion tons) it receives through its basin (Kumar et al., 2006). Here, one of the world's greatest rivers, the Lower Meghna River finds its way to the Bay of Bengal (Figure1). The Lower Meghna conveys the combined flows of the Brahmaputra (called in Bangladesh Jamuna), the Ganges, and the Upper Meghna. The sediment discharge from the Lower Meghna River is the highest (Coleman, 1969) and the water discharge, the third highest, of all river systems in the world (Milliman, 1991). The hydrodynamic factors that are playing dominant role in morphological development along the coast line of Bangladesh are; enormous volume of river water flow, sediment transport, strong tidal and wind actions, wave, salinity and cyclonic storm surge (Uddin et al., 2014). These hydrodynamic factors and their interactions create a complex pattern of sediment displacement in the estuary and shape the morphology of the estuary.
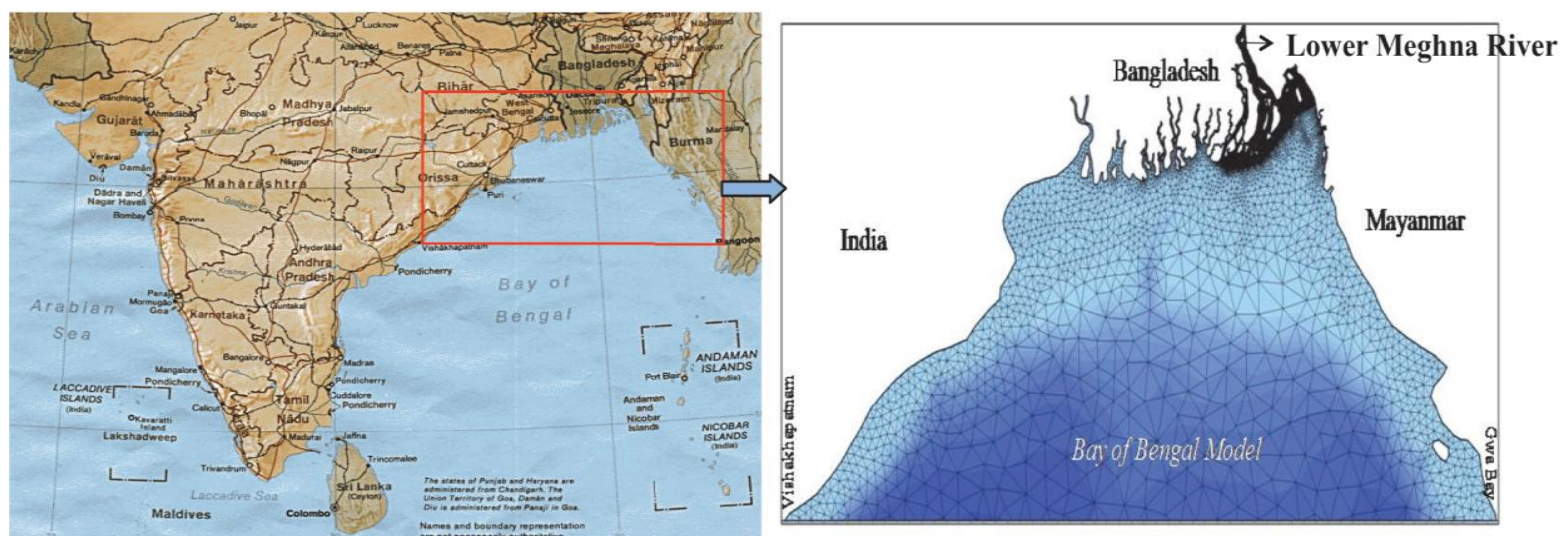

Figure 1: Model domain enclosed by shoreline of Bay of Bengal

The knowledge about the physical processes and morpho-dynamic behavior of the Lower Meghna Estuary system is still fairly limited. But to formulate long term development strategies in the region, it is very important to recognize the characteristics of different physical factors that contribute to the hydrodynamics and erosion-accretion processes through movements of sediment in the Meghna Estuary. Keeping this fact in mind, to enhance the knowledge of the complex hydrodynamic and morphological process in the Meghna estuary, a two dimensional general model of Bay of Bengal was developed under cyclone shelter preparatory study (CSPS, 
1998) undertaken by Bangladesh Government and the model was updated later during other projects. The morphology module is coupled to the hydrodynamic module in MIKE 21 Flow Model FM version of MIKE ZERO environment and they run in parallel. The present article focuses mainly on the calibration of morphology model with the help of satellite image generated sediment concentration data. This article also discusses development of model, its set-up, boundary conditions and few calibration results against observed data for the morphology model.

Remote sensing is a rapidly growing multidisciplinary science applied in coastal engineering research due to the ability to collect information regarding spatial and temporal question in a cost-effective way for the water resources engineers (Adam et al, 2015). During recent years many scientists have applied remote sensing technology to generate turbidity data, using which, it is possible to calculate sediment concentration data for a particular location, as there is established relationship between turbidity and sediment concentration.

Since the cohesive sediment transport modelling is still an empirical science and particularly for the Bay of Bengal, data used for calibration purpose is not continuous and not available for long duration say even for a complete tidal cycle, the calibration results are not coming always up to a satisfactory level. To overcome this constraint, effort is given in the present study to generate sediment concentration data with the help of satellite image and calibrate the sediment transport model more accurately and effectively.

\section{Methodology}

A mathematical model usually describes a system by a set of variables and a set of equations that establish relationships between the variables. MIKE 21HD simulates the water level variations and flows in response to a variety of forcing functions resolved on a rectangular or triangular grid covering the area of interest when provided with the bathymetry, bed resistance coefficients, wind field, hydrographic boundary conditions etc. The hydrodynamic module solves the vertically integrated equations of continuity and conservation of momentum in two horizontal dimensions. When the hydrodynamic model set up is prepared, simulated and calibrated properly then the sediment transport module is added to run the morphology model.

\subsection{Morphology Model simulation}

In the MIKE 21 FM modelling system, the transport of fine-grained material (mud) has been included in the Mud Transport module (MT), linked to the Hydrodynamic module (HD). In other words the cohesive sediment transport module is coupled to the hydrodynamic module and they run in parallel. The governing equation for sediment transport is solved on the same mesh and applies information on water levels and currents from the hydrodynamic module to calculate the sediment transport. The sediment transport module mainly solves the following advection-dispersion equation:

$$
\frac{\partial \bar{c}}{\partial t}+u \frac{\partial \bar{c}}{\partial x}+\mathrm{v} \frac{\partial \bar{c}}{\partial y}=\frac{1}{h} \frac{\partial}{\partial x}\left(h D_{x} \frac{\partial \bar{c}}{\partial x}\right)+\frac{1}{h} \frac{\partial}{\partial y}\left(h D_{\mathrm{y}} \frac{\partial \bar{c}}{\partial y}\right)+Q_{L} C_{L} \frac{1}{h}-\mathrm{S} \ldots \ldots \ldots \ldots \ldots
$$

Where $\bar{c}$ is depth averaged concentration $\left(\mathrm{g} / \mathrm{m}^{3}\right) ; \mathrm{u}, \mathrm{v}$ are depth averaged flow velocities $(\mathrm{m} / \mathrm{s}), D_{x}, D_{y}$ are dispersion coefficients $\left(\mathrm{m}^{2} / \mathrm{s}\right), \mathrm{h}$ is water $\operatorname{depth}(\mathrm{m}), \mathrm{S}$ is dispersion / erosion term $\left(\mathrm{g} / \mathrm{m}^{3} / \mathrm{s}\right), Q_{L}$ is source discharge per unit horizontal area $\left(\mathrm{m}^{3} / \mathrm{s} / \mathrm{m}^{2}\right), C_{L}$ is concentration of the source discharge $\left(\mathrm{g} / \mathrm{m}^{3}\right)$.

\subsection{Data used for model simulation}

Mainly four types of data were collected from secondary sources and were analyzed for hydrodynamic and morphology model set up preparation and simulation. The types of data used are: bathymetry or land level data, water level data, discharge data and sediment concentration data. Bathymetry data provides the land level or water-land boundary of model domain, water level data are used for boundary condition and calibration of HD model, discharge data also used for calibration of HD model and sediment concentration data are used for calibration of morphology model. Each type of data was checked for their consistency and only the consistent data were used for boundary and calibration purpose.

\subsection{Mesh Generation and Bathymetry Development}

Objective of mesh generation is to divide the whole model area in to a number of individual triangular flexible cells to perform the computation. To generate mesh, shoreline is essential. Shoreline can be extracted from satellite images using ARC View/ARC GIS or from MIKE-C Map. In case of BoB model shoreline is extracted from satellite images. Area included inside the shoreline represents a polygon (Figure 1). In case of BoB model one polygon should not be used. If coarser resolution is used for whole area then the estuary cannot be represented properly. Again if finer resolution is used to represent the Meghna estuary then the total number of computational points will be increased and simulation time will be higher. To avoid this situation and to represent the Meghna estuary properly, total model area is divided into four polygons of different resolution as shown in Figure 2. 


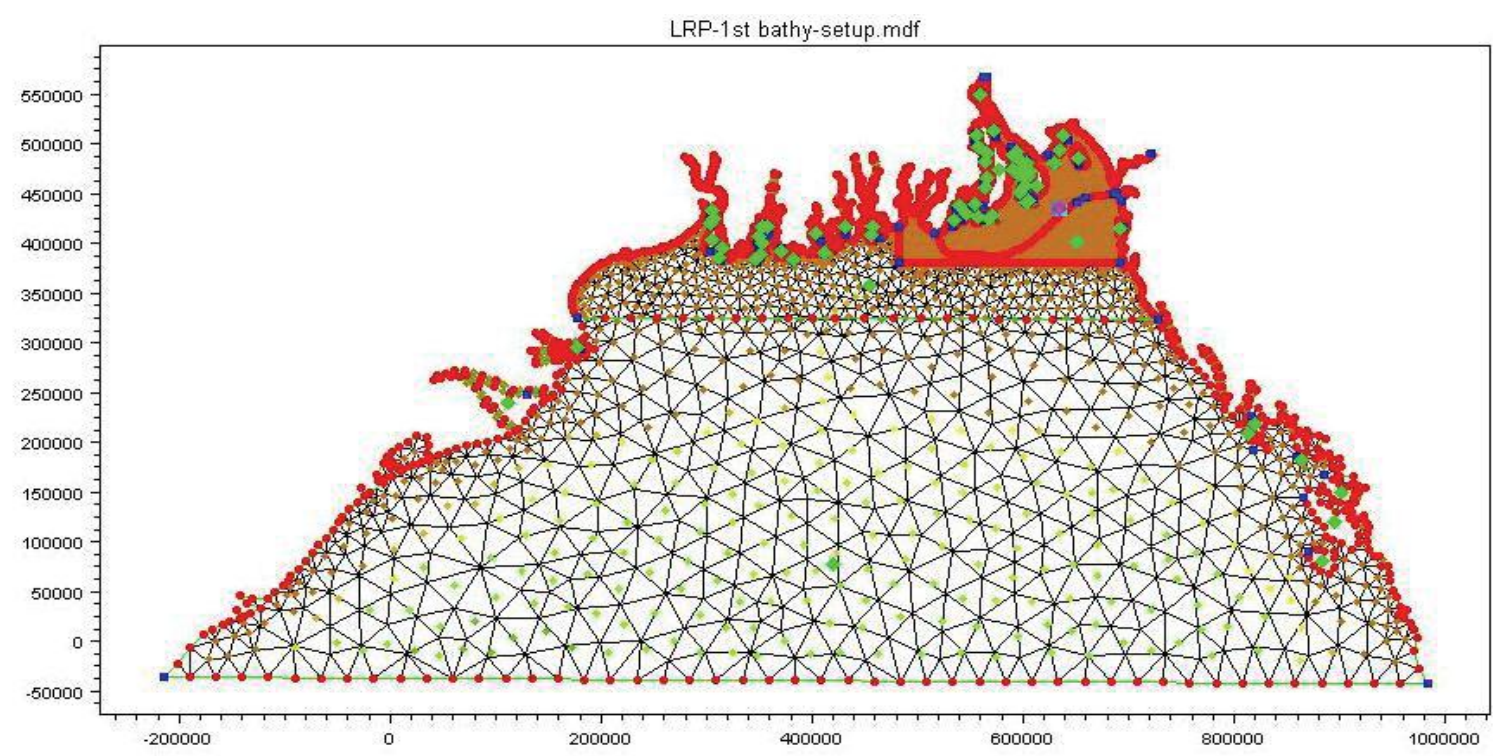

Figure 2: Different polygon and their mesh resolution in model domain

The resolution varies from $5400 \mathrm{~m} \times 5400 \mathrm{~m}$ and $1800 \mathrm{~m} \times 1800 \mathrm{~m}$ in the deep Bay of Bengal, through $600 \mathrm{~m} \times 600 \mathrm{~m}$ in the Meghna Estuary and $200 \mathrm{~m} \times 200 \mathrm{~m}$ in the areas of special interest. For bathymetry generation the measured and generated land level data were incorporated with the mesh and by applying the interpolation method, elevation in each and every point of the modeled area were calculated. The generated bathymetry is shown in Figure 3.

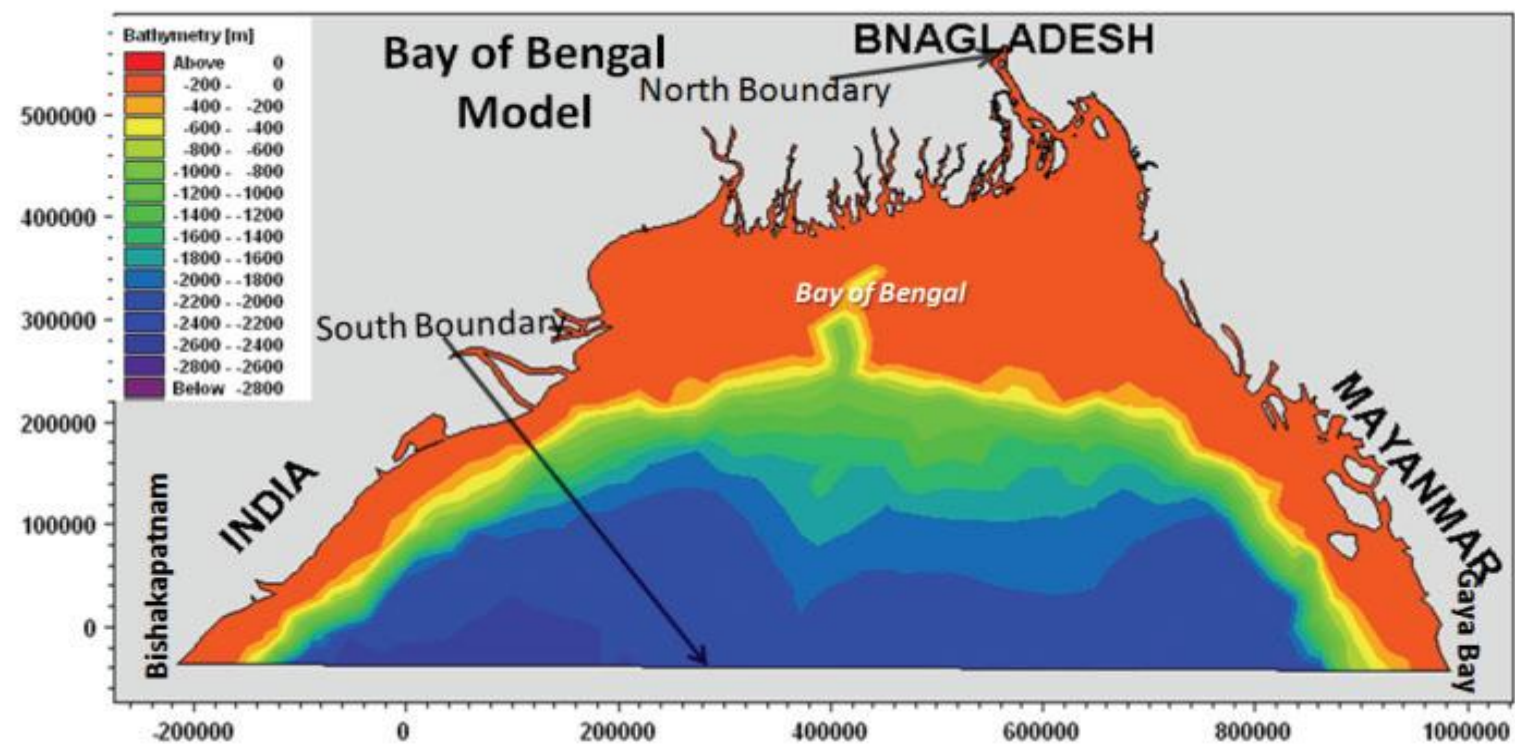

Figure 3: Generated bathymetry and open boundaries in Bay of Bengal model

\subsection{Boundary conditions of the model}

There are two open boundaries in the model, one is in the Lower Meghna River at Chandpur, which is northern boundary and another one is in the Bay of Bengal that is southern boundary as shown in Figure 3. Observed water level at Chandpur station has been used in the northern open boundary. Predicted or generated water level using Global Tide Model of two stations namely Vishakhapatnam (India) and Gwa Bay (Myanmar) was used for south open boundary. For sediment transport model, in the upstream boundary on the Lower Meghna River, suspended concentration of $350 \mathrm{mg} / \mathrm{l}$ has been applied. Zero sediment concentration has been assumed at the south boundary. Initial sediment concentration in the Meghna Estuary is also based on the field measurement. 


\subsection{Remote sensing technology in morphology model calibration}

Remote sensing technology is often applied for monitoring ocean water quality which involves mainly the estimation of suspended sediment concentration from sensor-derived radiance. Landsat Thematic Mapper (TM) imagery has been proven to be effective in mapping temporal and spatial variations in environment within large water bodies (Ray et al., 2013). For calibration of sediment transport model of Bay of Bengal, the available data and information are often scattered and limited. So, for better calibration of morphology model, generation of sediment concentration data can be made by using satellite image.

For accomplishing this objective, a correlation was established between DN values generated from image and observed turbidity. This relationship will be used to generate turbidity by using DN value of model simulation period, which can be easily extracted from simulation period image. This turbidity data will be used to calculate sediment concentration data since there is established relationship between turbidity and sediment concentration. Now the sediment transport model may be calibrated against sediment concentration data obtained from satellite image to bring the model performance to a satisfactory level.

\subsubsection{Method of generating DN Values}

The generic term for pixel values of satellite image is Digital Number or DN. It is commonly used to describe pixel values that have not yet been calibrated into physically meaningful units. DN values have been generated in ArcGIS 10.2 environment using Extract values to point under Spatial Analyst toolbox. Before calculating DN values a shapfile has been created containing the location of sample points where turbidity measurement has been taken. Then DN value has been calculated and transferred in the sample location shapfile. To generate DN value, Landsat Images 8 OLI dated 17.12.13 has been used.

\section{Results and Discussion}

In order to include the transport and deposition processes of fine-grained material in the modelling system, it is necessary to integrate the description with the advection-diffusion equation caused by the water flow (DHI 2012). In the MIKE 21 Flexible Mesh, FM modelling complex, the transport of fine-grained material (mud) has been included in the Mud Transport module (MT), linked to the Hydrodynamic module (HD). In other words the cohesive sediment transport module is coupled to the hydrodynamic module and they run in parallel. The governing equation for sediment transport is solved on the same mesh and applies information on water levels and currents from the hydrodynamic module to calculate the sediment transport.

\subsection{Calibration results of morphology model with observed data}

The two-dimensional sediment transport model of the Bay of Bengal have been calibrated against suspended sediment concentration at different locations comparing the model results with field measurement to make the model performance to a satisfactory level. Depending upon the availability of collected data, the sediment transport model was simulated for the period of April '2009 to February 2010 so that it covers Monsoon and dry season. Locations of calibration areas have been presented in Figure 4 and few calibration plots are presented in Figure 4.1 and 4.2.
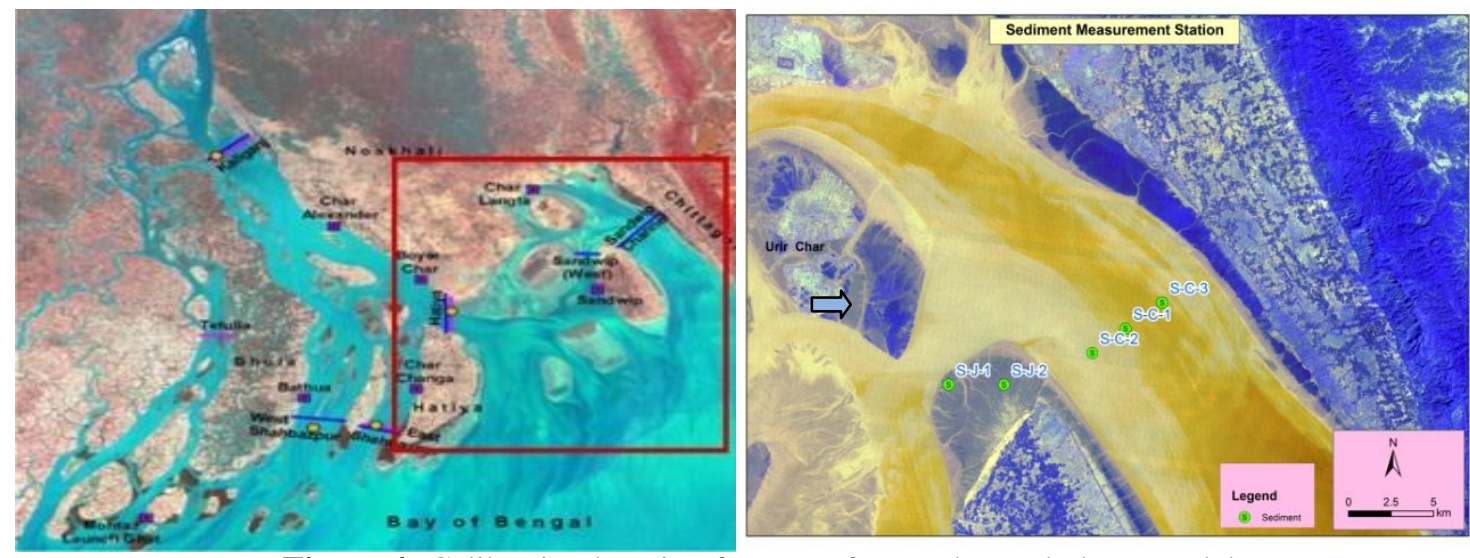

Figure 4: Calibration location for Bay of Bengal morphology model 


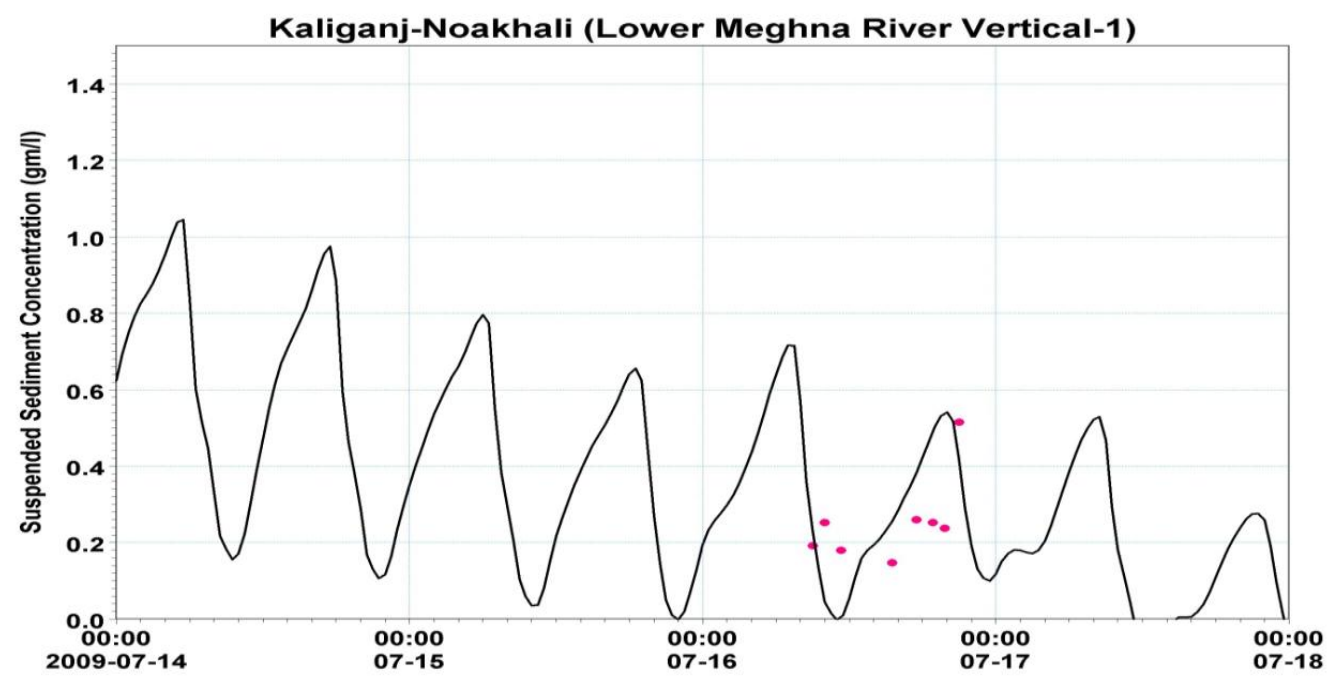

Figure 4.1: Calibration result near Kaliganj in Lower Meghna River (July 2009)

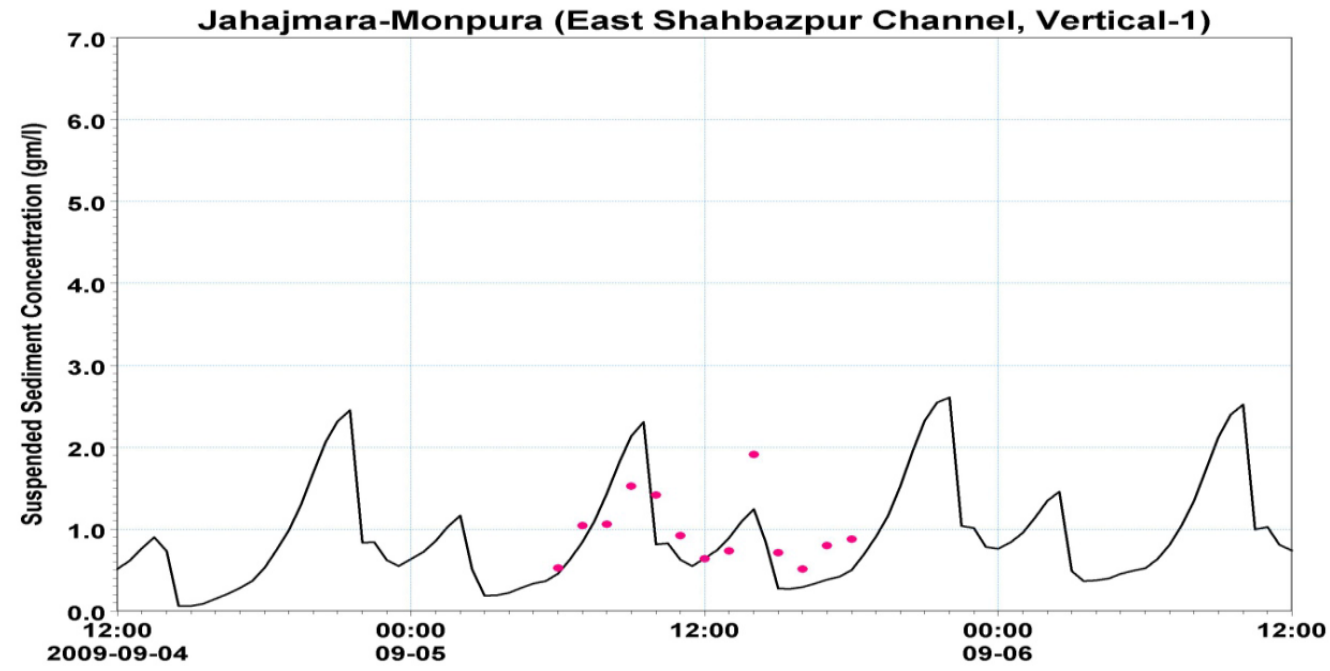

Figure 4.2: Calibration result in East Shahbazpur Channel (October 2009)

\subsection{Calibration of morphology model using remote sensing technology}

Cohesive sediment transport calculations are influenced by significant uncertainties, and cohesive sediment transport modelling is still an empirical science. At the same time the required information is often scattered and limited. Moreover, data used for calibration purpose is not continuous and not available for long duration say even for a complete tidal cycle. So the calibration results are always not coming according to expectation. To overcome such situation effort has been made to generate sediment concentration data with the help of remote sensing technology and calibrate the sediment transport model with this generated data in a better way.

To do so, a correlation has been established between observed turbidity in the field for a specific time and DN values extracted from satellite image for the same time. For this case, $17^{\text {th }}$ December, 2013 image was used and it is shown in Figure 5 (a). DN value has been calculated for six different bands (B1-B6), are shown in Table 1. But for establishing correlation with turbidity, DN value of Band 2 has been used since this band corresponds to turbidity of water body of an image. The relationship plot of turbidity and DN value has been shown in Figure 5. With generated equation. Now, by using this correlation, turbidity has been calculated from the DN value of images of simulation period to calibrate the sediment transport model. These images for generating concentration data are shown in Figure 5 (b), (c) and (d). As there is established relation between turbidity and sediment concentration, easily the turbidity data calculated from DN values may be converted to sediment concentration Hung et.al. (2014). 
Application of Remote Sensing Technology for Calibration of Bay of Bengal Morphology Model

Table 1: Calculated DN values from image (17/12/2013) against observed turbidity:

\begin{tabular}{|l|l|l|l|l|l|l|l|l|}
\hline & \multicolumn{7}{|l|}{ Band Number } & B \\
\hline Longitude $\left(^{\circ}\right)$ & Latitude $\left(^{\circ}\right)$ & B1 & B2 & B3 & B4 & B5 & B6 & Turbidity (NTU) \\
\hline 91.59 & 22.31 & 9899 & 9482 & 9161 & 9100 & 6199 & 5177 & 687 \\
\hline 91.71 & 22.26 & 9870 & 9419 & 9097 & 8770 & 6491 & 5210 & 632 \\
\hline 91.61 & 22.18 & 9861 & 9433 & 9150 & 8900 & 7788 & 5189 & 647 \\
\hline 91.73 & 22.31 & 9861 & 9407 & 9120 & 8750 & 6412 & 5237 & 642 \\
\hline 91.60 & 22.09 & 9846 & 9442 & 9160 & 9006 & 7198 & 5186 & 656 \\
\hline 91.68 & 22.21 & 9916 & 9324 & 9080 & 8700 & 6882 & 5196 & 608 \\
\hline 91.73 & 22.36 & 9758 & 9421 & 9140 & 8726 & 6465 & 5174 & 642 \\
\hline 91.72 & 22.32 & 9859 & 9419 & 9105 & 8745 & 6486 & 5234 & 628 \\
\hline 91.57 & 22.24 & 9868 & 9365 & 9120 & 8650 & 7081 & 5161 & 613 \\
\hline 91.64 & 22.31 & 9851 & 9445 & 9151 & 9007 & 7370 & 5161 & 667 \\
\hline
\end{tabular}

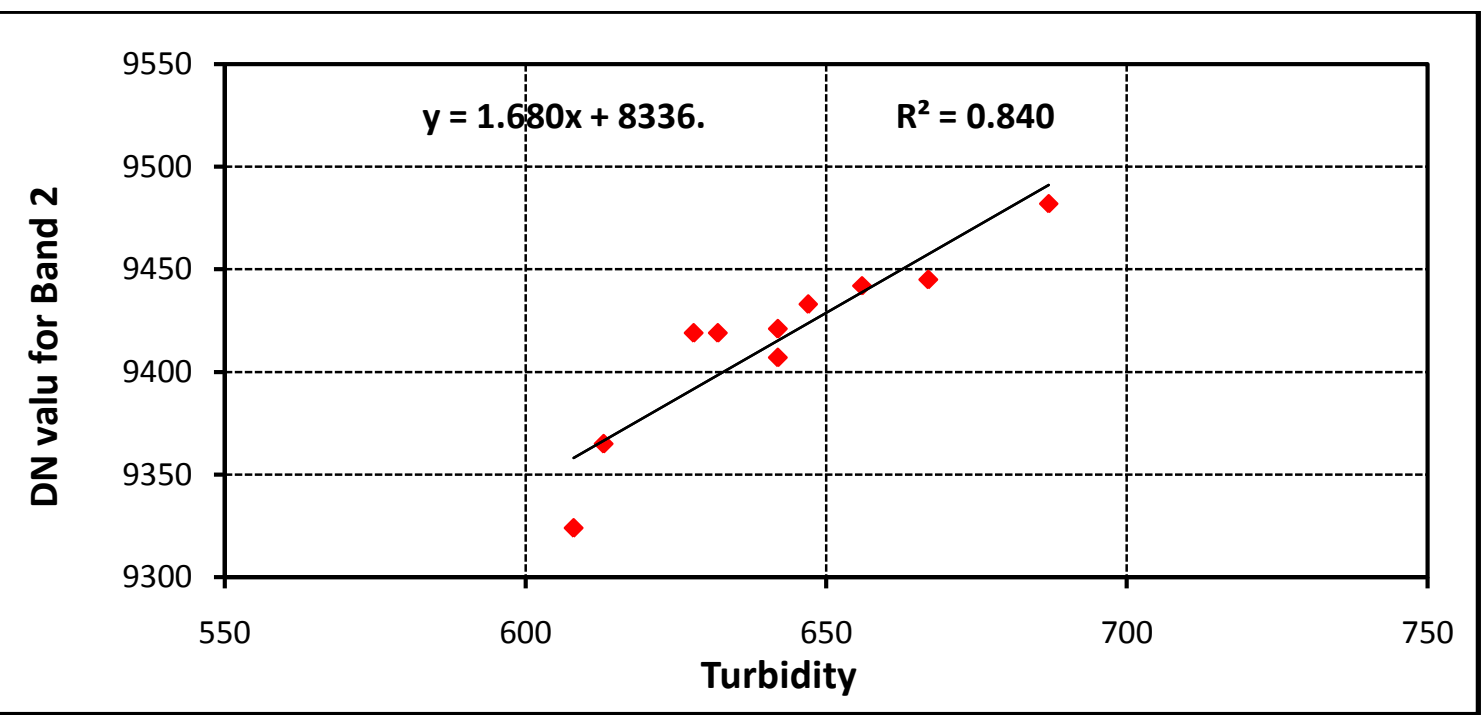

Figure 5: Correlation between DN values extracted from image of 17/12/2013 and turbidity

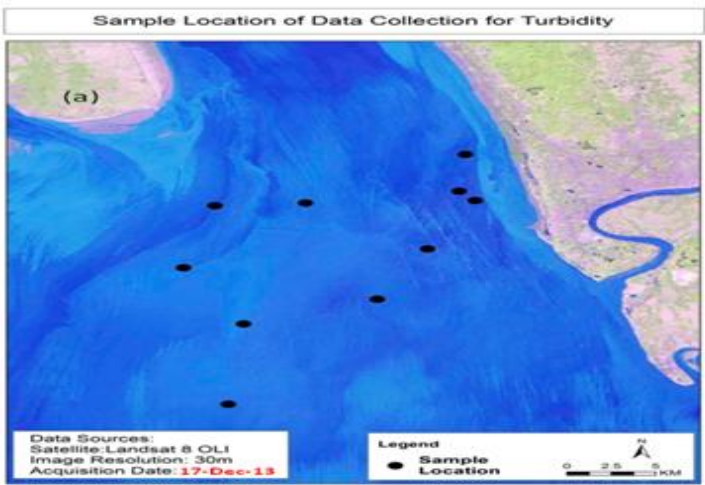

Sample Location of Data Collection for Turbidity

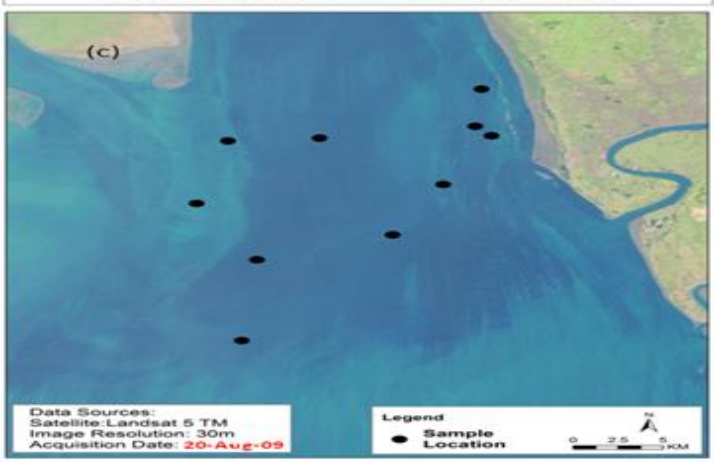

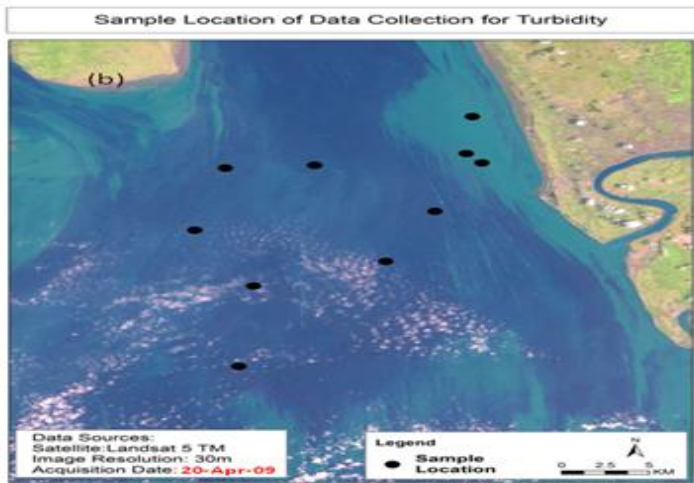

Sample Location of Data Collection for Turbidity

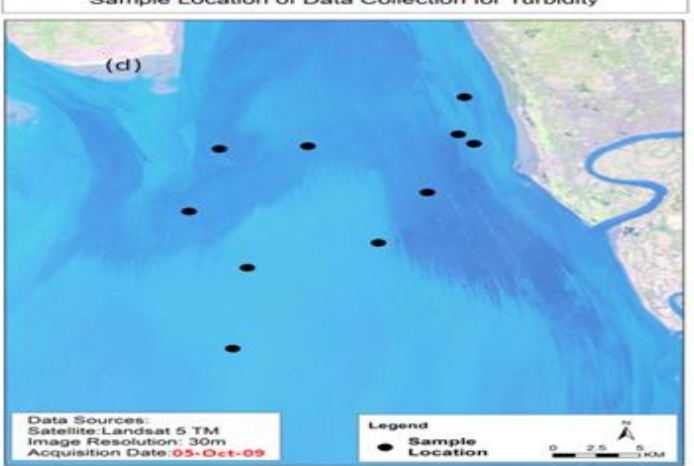

Figure 5: (a) Image, that was used for extracting DN value to establish correlation with turbidity, (b), (c) and (d) Images, those were used to generate DN value for calculating sediment concentration to calibrate sediment transport model. 
By using the above relationship shown in Figure 5, sediment concentration was calculated for the model simulation period to calibrate the model. Calibration results of sediment transport model by comparing the simulated sediment concentration and generated sediment concentration by using correlation has been presented in the Figures 5.1 and Figure 5.2. A typical calculation format for sediment concentration by using image, for a particular location, is shown in the table 2.

Table 2: Calculation of suspended sediment concentration in $\mathrm{kg} / \mathrm{m}^{3}$ from image, for a location:

\begin{tabular}{|c|c|c|c|c|}
\hline Date of used image & $\begin{array}{l}\text { DN value extracted } \\
\text { from image }\end{array}$ & $\begin{array}{l}\text { Turbidity (NTU) calculated by } \\
\text { using the equation in Fig: } 5.15\end{array}$ & $\begin{array}{l}\text { SCC }(\mathrm{mg} / \mathrm{l}) \text { calculated by Hung } \\
\text { et.al. }(2014)(\operatorname{col} 3 * 1.15)\end{array}$ & $\begin{array}{l}\mathrm{SCC} \\
\mathrm{kg} / \mathrm{m}^{3}\end{array}$ \\
\hline 20-04-09 0:00 & 8380.05 & 26.09 & 30 & 0.03 \\
\hline 22-04-09 0:00 & 8456.20 & 71.39 & 82.1 & 0.0821 \\
\hline $18-08-090: 00$ & 8485.29 & 88.70 & 102 & 0.102 \\
\hline 19-08-09 0:00 & 8572.99 & 140.87 & 162 & 0.162 \\
\hline 21-08-09 0:00 & 8502.83 & 99.13 & 114 & 0.114 \\
\hline $22-08-09$ 0:00 & 8404.90 & 40.87 & 47 & 0.047 \\
\hline 03-10-09 0:00 & 8552.52 & 128.70 & 148 & 0.148 \\
\hline 04-10-09 0:00 & 8584.68 & 147.83 & 170 & 0.17 \\
\hline $05-10-09$ 0:00 & 8540.83 & 121.74 & 140 & 0.14 \\
\hline 06-10-09 0:00 & 8430.18 & 55.91 & 64.3 & 0.0643 \\
\hline
\end{tabular}

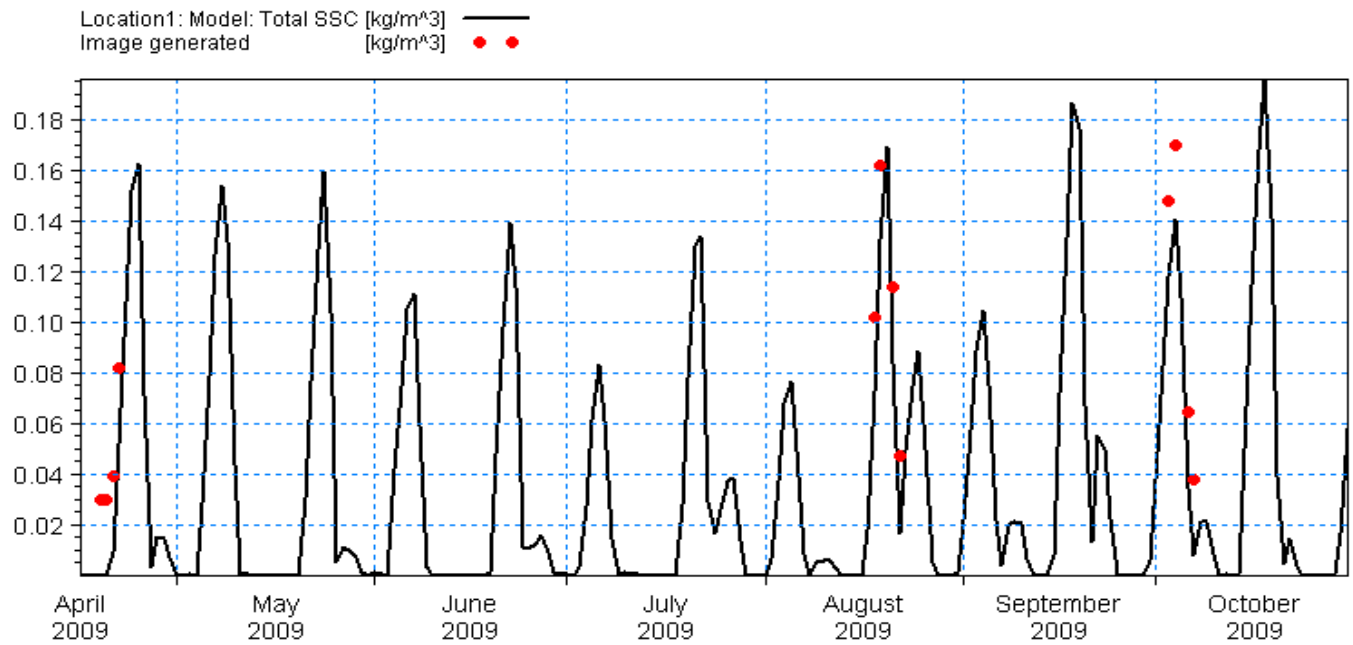

Figure 5.1: Calibration of sediment transport model against image generated sediment concentration at location 1.

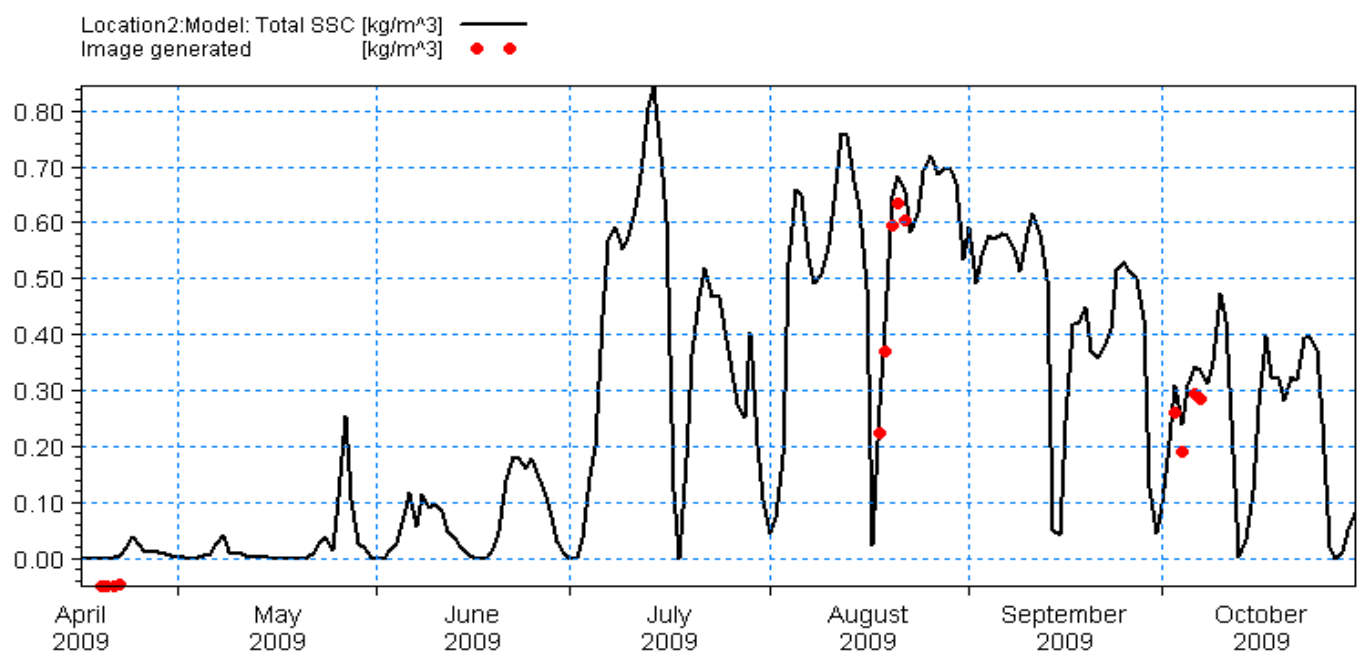

Figure 5.2: Calibration of sediment transport model against image generated sediment concentration at location 2. 
Lewis and Eads (2001) also reported there is a linear relationship between turbidity and total suspended sediments (TSS). They showed that, TSS $=0.95 *$ turbidity for river water. In the present study for coastal water, turbidity was multiplied by 1.15 to obtain sediment concentration in $\mathrm{mg} / \mathrm{l}$ following the study of Hung et.al. (2014).

\section{Conclusion}

The calibration results with the approach of using remote sensing technology shows good agreement with the model generated sediment concentration. So this technique may be used for calibration of sediment transport model, where the observed data are not available. For this purpose satellite image should be recorded in regular basis to produce turbidity data. Moreover a relationship should be established particularly for the Bay of Bengal to convert the turbidity data in to sediment concentration. This may be done by collecting the turbidity data and sediment data for same time in the same region.

\section{References}

[1]. Adam, M.; Spicer, K. R.; Tami, C. and Uhrich, M.A. 2015, Estimating concentrations of fine-grained and total suspended sediment from close-range remote sensing imagery, Conference paper, Conference Title:SEDHYD 2015, Reno, Nevada, 19-23 April, 2015.

[2]. Coleman, J.M. 1969, Brahmaputra River: Channel process and sedimentation, Sediment Geol., 3(196), pp: 129-239.

[3]. CSPS 1998, Cyclone Shelter Preparatory Study, Stage I: Feasibility Phase. Final Report. Mathematical Modelling of Cyclone-Surge and Related Flooding. European Commission, Directorate General External Economic Relations, Technical Unit for Asia Centre, 1998.

[4]. DHI, 2012, MIKE 21 \& MIKE 3 flow model FM: Mud Transport Module, Scientific Documentation, DHI, Denmark.

[5]. Hung, T.L. and Tuyen, V.D. 2014, Estimating suspended sediment concentrations in surface water of tri an lake (Vietnam) using landsat multispectral images, VestnikOrelGAU, 3(48), June 2014.

[6]. Kumar, S. P., Sardesai, S., Ramaiah, N., Bhosle, N.B., Ramaswamy, V., Ramesh, R.,Sharada, M.K., Sarin, M.M., Sarupriya, J.S. and Muraleedharan, U. 2006, Final ReportSubmitted to the Department of Ocean Development New Delhi, Bay of Bengal ProcessStudies.

[7]. Lewis, J. and Eads, R. 2001, Turbidity threshold sampling for suspended sediment load estimation, Proceedings of the Seventh Federal Interagency Sedimentation Conference, March 25 to 29, 2001, Reno, Nevada.

[8]. Milliman, J.D. 1991,Flux and fate of fluvial sediment and water in coastal seas. In: Mantoura, R.F.C., Martin, J.-M. \& Wollast, R. (eds). Ocean Margin Processes in Global Change, John Willey and Sons Ltd., Chichester, pp: 69-89.

[9]. Ray R, Mandal S, Dhara A, 2013, Environmental monitoring of estuaries: Estimating and mapping various environmental indicators in Matla estuarine complex, using Landsat TM digital data, International Journal of Geomatics and Geosciences, Volume 3, Issue 3, pp: $570-581$

[10]. Uddin, M., Alam, J.B., Khan, Z.H., Hasan, G.M.J. and Rahman, T. 2014, Two Dimensional Hydrodynamic Modelling of Northern Bay of Bengal Coastal Waters, Computational Water, Energy, and Environmental Engineering, 3, pp: 140-151. http://dx.doi.org/10.4236/cweee.2014.34015. 